\title{
The Analysis on Mechanism and Application of Cementitious Capillary Crystalline Waterproofing Coating
}

\author{
Guo-Zhong LU ${ }^{1, a^{*}}$, Wei-Xuan ZHAO ${ }^{1, b}$, Li-Juan ZHOU ${ }^{1}$, Xiu-Juan DING ${ }^{2}$ \\ ${ }^{1}$ State Key Laboratory of Solid Waste Utilization in Building Materials, Beijing, 100041, P.R.China \\ ${ }^{2}$ Northeastern University at Qinhuangdao, Qinhuangdao, Hebei, China, 066004, P.R.China \\ aluguozhong@163.com, bdingxiujuanlove@126.com \\ ${ }^{*}$ Corresponding author
}

\begin{abstract}
Keywords: Cementitious, Waterproofing Coating, Waterproofing Mechanism, Technological Process, Application Future.
\end{abstract}

\begin{abstract}
Cementitious capillary crystalline waterproofing coating is a new-type waterproofing agent. It makes up for many shortcomings of traditional waterproofing coating on properties and application. The paper described the waterproof mechanism in detail. The main characters, the technological process, the application future and the main weakness were also introduced, which has a very important significance to produce the high quality cementitious capillary crystalline waterproofing coating and on futher exploration.
\end{abstract}

\section{Introduction}

Cementitious capillary crystalline waterproofing coating is a kind of powdery material substrated on cement and quartz sand, incorporated into a variety of active chemical substance. The active chemical substance of this kind of coating carried by water or osmosis, which transports in the microporous and capillary of the concrete, filling the particles and the incompletely hydrated components. It can form insoluble branches and tendrils of crystal, combined with the concrete as a whole to make up the microfracture by hydrating once again[1].It can be used for positive side waterproofing and waterproofing dorsal surface, and more suitable for wet substrate surface construction.

Such material abroad has nearly a hundred years of history. First, the United States invented the waterproof cement-substrated metal oxide material in 1906; In 1942,German chemist (Louis • Jason) Louritz Jeusem invented and named Cementitious Capillary Crystalline Waterproofing Material in practice to solve the water leakage in the cement ship, which was CCCW for short. It spreaded from Europe to North America in the middle of 1960's and carried round Canada in 1966. The main advantage of this material is its good impermeability and self-healing ability, strong adhension, good corrosion resistance, and innocuity side effect. It has obvious advantages of being rapidity and reliability in construction compared with other waterproof materials. Concrete waterproofing has been very widely applied in Europe, America, Canada, Japan, Singapore and other countries at present. And it was unanimously praised in the engineering sector[2].It was introduced in China from the 1980's, and it had always been monopolized by the imported products in the past. At present, the Chinese enterprises that product and distribute the cementitious capillary crystalline waterproofing coating are mainly divided into two kinds of types .One method is to import raw materials from abroad , and then produce by themselves. The other is to import products from abroad directly, and sold by agent. The national standard (GB18445-2001) has increasingly being used in various water projects, especially in hydraulic, tunnels and basement waterproofing since March 1, 2002, and the performance of the product has also been recognized increasingly.

Currently, the mechanism of rigid cement-based waterproof material with better application effect is that the waterproof can only work on the surface .It cannot penetrate into the internal structure automatically and deeply so that it does not have a permanent waterproofing effect. As time passed by, it degenerated continuously. Once the waterproof layer has been destroyed, the waterproof ability also disappeared and easily led to alkali-aggregate reaction(AAR)[3]. In order to overcome these weaknesses, 
the cementitious capillary crystalline waterproofing coating that had the characteristic of self-healing, capillary crystalline and the negative side water construction was developed. But due to a large profit margin, some enterprises scramble for profit and lead to some confusion in the cementitious capillary crystalline waterproofing coating market. The quality of product varies greatly. Therefore, it is particularly important to have a good understanding of its characteristics , mechanism, and construction technology in order to produce and develop a kind of cementitious capillary crystalline waterproofing coating with excellent performances.

\section{The Analysis on Characteristics and Mechanism of Cementitious Capillary Crystalline Waterproofing Coating}

\section{The Main Characteristics of Cementitious Capillary Crystalline Waterproofing Coating}

(1) Self-healing. It can close the microfracture that is no more than $4 \mathrm{~mm}$ with the self-healing function. The active substance closed by the coating can cause secondary crystallization at the defects of the substrate when encountering water, so it can repair microcrack automaticlly. Because the hole of the cementitious capillary crystalline waterproofing coating is smaller and less, a large part of the active substances are blocked in the coating . Polymeric or oligomeric active substance can make the coating active. In the case of water, the active materials release automatically, and may go into deeper with water once again. And it can form stable crystal by polymerization to prevent water, so it may play a role in remedying a defect automatically. The waterproofness increased with time, making the waterproof ability reach the maximum.

(2)Breathable function. The active materials form acicular crystals after polymerization. Large molecules or high polymer with more hydrophobic group will reduce the surface tension of crystal, which is filled in the pore. And it cannot absorb water. However, the crystal is not a dense structure, the moisture gas can pass, but liquid water cannot.

(3)Permanent waterproof. Since the material is a inorganic, there is no aging problem. The catalyst will be activated when encountering water, and produce new crystals with self-healing function. The waterproof effect is perpetual without loss of catalyst during the catalytic reaction process.

(4)It can be used on wet surface or the surface of initial setting concrete and mortar to reduce the construction period.

(5) It will form a complete whole with concrete by positive side and negative side construction. Do not afraid to be broken, hit and torn after the coating solidified completely. Its service life is the same as structural body.

(6) The respiratory function allows concrete internal moisture gas to pass and keeps the structure dry.

(7) It can prevent the concrete from corroding by chemicals and the harsh environment effectively. It can also enhance the strength of concrete and prevent reinforcement from corrosion.

(8) The product is non-toxicity, no smell, no burning, no blast .It can be used in the drinking water project.

\section{The Working Principle of Cementitious Capillary Crystalline Waterproofing Coating}

The main working principle of cementitious capillary crystalline waterproofing coating is that the active substances penetrate into the internal part of concrete by seepage, ion concentration gradient or normal capillary action of concrete[4]. Active substances react with unhydrated cement particles, so it can promote hydration and produce insoluble needle-like crystal, blocking water and other liquid from any direction, achieving such functions, permanent waterproof and damp proof, protecting steel bar and improving the structural strength of concrete. When concrete is dry, the active substance is in dormant state. While there is water infiltrating, the substances continue to hydrate and form the new crystalline, so as to achieve the purpose of permanent waterproof.

First, there must be seepage pressure for coating permeability . It is capillary pressure of the concrete. The larger surface tension between solid and liquid is, the smaller wetting angle will be, and the stronger its penetrating ability will be. After active substance of waterproofing coating reacting with concrete, the waterproofing materials formed a high ion concentration on the surface of concrete. The concentration 
gradient created the conditions for the permeability. Ion migrated from high concentration to low concentration. Active substance and its gelation composition migrated to the pores of the cement surface . The penetration depth of active substance is not only related to the looseness of substrate material, but also the residence time of the active substances on the substrate surface. The more looseness the substrate material is, the longer the residence time of the active substances on the substrate surface will be, and the deeper the penetration depth of active substance will be. Under normal circumstances, the new crystalline produced by active substance of cementitious capillary crystalline waterproofing coating can fill the defects and pores in the $5 \mathrm{~mm}$ to $50 \mathrm{~mm}$ depth of concrete surface, making it a rigid waterproof layer with good impermeability. Active substances are solid materials. Its waterproof function due to the polymerization reaction and catalytic reaction. Small molecular or low molecular with high activity formed macromolecule, catalyzing unhydrated cement particles to produce crystal, blocking penetrating passage ,and then realized high efficient waterproofing. Because the active substance is in the water, the polymerization of small molecular or low molecular can only poly on the surface, the active substance cannot deeply penetrate the substrate to crystallize. In order to make the active small molecules have a good permeability, sufficient wetting treatment should be carried out before construction ,so that small molecules crystallize at the defects of the deep substrate. The penetration depth of active substance is not only related to the entering depth of water, the looseness of substrate material, but also the residence time of the active substances on the substrate surface .

Secondly, the coating had a good crystal property. Under normal circumstances, only 25 percent of cement concrete was fully hydrated. As time went on, the calcium ion $\left(\mathrm{Ca}^{2+}\right)$ and Silicon ion $\left(\mathrm{SiO}_{3}{ }^{2-}\right)$ for cement crystallization and its growth reduced gradually. It was the main reason for crystal hyperplasia. Take advantage of the permeability and catalysis to improve cement crystals. Just like the secondary activated cement, since osmotic substance is misprinted ion with small size, it can spread naturally with water in the subtle space. The state is aways remained to make sure the reaction continue to carry out . The minimum concentration is only $0.01 \mathrm{ppm}$ when reaction occurs ,therefore the catalyst is a highly active chemical. The basic reaction mechanisms are as follows.

1) The material was a ideal material for negative side waterproof of concrete structures. The mechanism was penetration effectiveness, that high salt solution seepaged to the low salt solution through the capillary of concrete[5].

2) Free calcium oxide and moisture are two important factors of materials. In view of the free calcium oxide spread all over the concrete, and as long as the concrete structure seepaged water, there was moisture. Thus these two conditions are easily to possess. In addition, wetting the dry concrete, cleaning the surface of concrete is necessary to protect the capillary unblocked.

3) The basic condition for the material to react and form crystallization is moisture, free calcium oxid and chemicals. The two elements, moisture and free calcium oxid, if they always exist in the capillaries of concrete, and the crystal formation will be uninterrupted. If the two elements lack of one, the chemical reaction will be terminated, and the active crystals will be kept in the capillaries of concrete. Once seepage water infiltrate into the concrete again, the active crystals resume the reaction of crystal growth, filling the capillary continuously. Then it can improve densification and enhance impermeability capacity.

4) The material is a complex of calcium. It can spontaneously spread with water in the subtle space and catalyze. It will promote the production of cement crystals continously, coating the concrete base and achieving impermeability and waterproof. The complex of calcium spread in the water of concrete gap and react with reactive $\mathrm{SiO}_{3}{ }^{2-}$ to form calcium silicate that precipitate into the pores of the concrete. The replaced complex will form new complex with calcium in concrete system continuously, then react with reactive $\mathrm{SiO}_{3}{ }^{2-}$ again and produce new crystals. The crystal produced by hydration reaction may usually increased to $0.4 \mathrm{~mm}$ which is bigger than the maximum size of concrete capillary diameter. It is also the maximum width of the crack can be applied, so that the concrete is dense and waterproof.

\section{The Formation of Cementitious Capillary Crystalline Waterproofing Coating Crystals}

The active substances of cementitious capillary crystalline waterproofing coating play a major role in the following two aspects. First, it can form acicular crystals by themselves. The second aspect is calcification reaction which can catalyze calcium of cement to form colloidal crystals. The formation condition of crystals is that the concentration of the active substance solution increased and carried out 
polycondensation crystallization. When crystalline active substance was used in the cement hydration or on the wet surface of cement products, active substance was dissolved in water and dispersed in the cement base with water. But it was involved in hydration reaction as time passed by. Part of water volatiled, causing the concentration of the active substance solution to increase and carry out polycondensation crystallization. Polycondensation crystallization caused by reduced alkaline. The active substances absorbed $\mathrm{CO}_{2}$ in the air and acidic or weakly alkaline substances from the surrounding environment ,then the $\mathrm{pH}$ of solution decreased. When the $\mathrm{pH}$ is less than 12 , active small molecules will poly automatically, catalyzing unhydrated cement particles to produce crystal, and then realize high efficient waterproofing. Fig. 1 is the crystal morphology of coating produced in concrete.

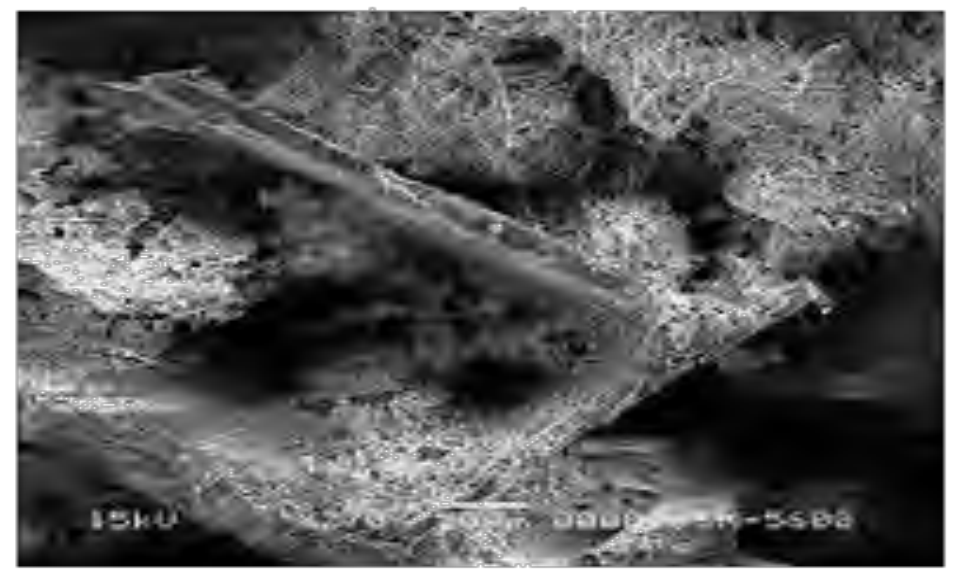

Fig.1 The Crystal Morphology in Concrete

\section{The Discrimination of Cementitious Capillary Crystalline Waterproofing Coating}

At present, there are two types of inorganic powder waterproof coatings in the market. They are very similar in appearance. One is the membrane formed powder coating, the waterproof principle is that coating can depend on its density to block water. The other is capillary crystalline powder coatings, active substances penetrated the substrate and formed crystals to block pores, achieving plugging. Usually distinguish these two types of powder waterproof material in the following way.

1) Secondary permeability detection. The non-capillary crystalline waterproofing material cannot recrystallize after a permeable test, which has been verified by expert over and over again. That is, it does not have the self-healing function. Its secondary impermeability pressure is small, such materials can not meet the standard requirements of GB18445-2001. On the contrary, cementitious capillary crystalline waterproofing coating can meet the standard requirements with good secondary impermeability pressure. However, the secondary permeability pressure testing costs two months with complicated operation and high costs.

2)Automatic repair test. Coating water flume with capillary crystalline waterproofing materials, which is made by strong permeable hollow bricks or aerated concrete, lightweight block ,etc. Under the conditions of $(25 \pm 2)^{\circ} \mathrm{C}$ and relative humidity greater than $60 \%$,standing for 2 days, filling in the tank with water, the wet spot can be seen after about $30 \mathrm{~min}$ outside the tank. Keep the water level inside the tank and observe the wet spots situation every day, the wet spots gradually disappear after one week. The test can test capillary crystalline material with the function of self-healing and blocking pores.

3 ) Penetration function tests. The active substance of capillary crystalline material can penetrate into the interior of material and produce crystals. But membrane formed materials do not have this feature. We can make two concrete specimens respectively. One was painted capillary crystalline material on the positive side, and the other was painted conjunctival materials. Under the conditions of $(25 \pm 2)^{\circ} \mathrm{C}$ and relative humidity greater than $60 \%$,spraying three times a day with clean water. To do the impermeability test after a 7-day conservation. When the water penetrated through the test block, removed the test block and dried naturally for seven days. Then to break the test block and observe the crystal of the concrete block cross-section with a microscope. 


\section{The Construction Technology of Cementitious Capillary Crystalline Waterproofing Coating}

Operations must be carried out in the application process in accordance with the construction technology, otherwise it can not give full play to the performance of the material. The construction technology and precautions are as follows.

\section{The Construction Technology}

(1) Substrate treatment. Remove loose, oil and putty to expose the surface of the cement, and then fully wet the substrate to be saturated that can provide a fully opened capillary to improve permeability. As for the crack and defects appeared on the surface of the structure, it need to be repaired by Capillary crystalline waterproofing mortar firstly, and to brush the capillary crystalline waterproofing coating next.

(2) Mixing materials. Add water into the powder, and the powder/water ratio is 4 to 1 . Stir uniformly until it reached the consistency can be coated, controlling water cement ratio strictly when construction.

(3) Operation. Brushed the mixed slurry on the substrate uniformly, and the thickness cannot be less than $1 \mathrm{~mm}$. Slurry should be used within 30 minutes, stirring when material get thicken(Add water is not allowed). Mix the slurry when using it. When brush the second layer, must make sure the first layer is still wet. If the first layer is too dry, wetting the coating, and go on. Coating should be uniform, and anywhere should not be missed. Focus on the dull corner, and stir the slurry uniformly, precipitate phenomenon should not appear to avoid coating cracking.

(4) Maintenance. Must avoid coating being damaged by fog curing after the initial setting. Spray at least 3 times per day, for 2-3 days. Spray several times on a hot day, or relatively dry weather to avoid coating drying too early, which has an impact on permeability. After the construction is accomplished, preventing rain and low temperatures below $2{ }^{\circ} \mathrm{C}$ within 48 hours. The tanks, such as pond, water storage tank must be conserved three days, then placed 12 days before injecting liquid.

\section{Precautions}

(1) Don't construct in the rain or the ambient temperature is below $4{ }^{\circ} \mathrm{C}$.

(2) Use in the morning or evening on a hot day ,so as not to affect the permeability.

\section{Prospects and Research Directions}

Currently, cementitious capillary crystalline waterproofing materials belong to a new cutting-edge product with higher added value. Material cost is expected about 10 yuan per Kg. The market price of such products, domestic products is 18 yuan to 30 yuan per $\mathrm{Kg}$, and foreign product generally 30 yuan to 40 yuan per Kg. The profit is about 10 yuan to 20 yuan per Kg. If sell 100-200 tons, then there will be 200-400 million profits a year, thus manufacturer can obtain high economic benefit in this way.

Because cementitious capillary crystalline waterproofing materials have good self-healing function, in foreign countries, it has been widely used in the underground structures of industrial and civil construction, subways, bridges roads, drinking water plants, sewage treatment plants, etc. But, at present, the product quality of this kind of product varies greatly that affects the application of these materials to a great extent. In addition, cementitious capillary crystalline waterproofing materials are mostly imported from abroad or formulated at home with the key material, active fillers, which are imported. As a result, the cost of product is higher, and market prices remain high, up to thirty or forty thousand yuan per ton on average. Our self-developed product, because of its poor activity, its low secondary impermeable pressure and poor self-healing ability, making the durability of material poor, which affects the wide application of the material to some extent.

The material overcomes such disadvantages. For example, flexible waterproof materials require a high moisture content, construction is tedious and it may cause pollution. And it has improved the poor complaisance of the traditional rigid waterproof material with the change of the substrate. Its good self-healing properties and environmental performance is also a traditional waterproof materials can not match.

However, there is a big controversy about some performance tests and indicators in the national standards of this coating, being discussed and revised. For example, there are some objections about the important indicator of its crystal permeability and self-healing functions, the test methods and test time of 
second impermeable pressure, the preparation of impermeability reference specimen. Penetration depth testing of the active material, different opinions about formation and morphology of crystal need to be further studied.

\section{Conclusion}

Cementitious capillary crystalline waterproofing coating is a new-type waterproofing agent, with good self-healing ability, breathable, environmental protection, waterproofing permanently and other features, which overcomes such disadvantages that flexible waterproof materials require a high moisture content, construction is tedious and it may cause pollution. And it has improved the poor complaisance of the traditional rigid waterproof material with the change of the substrate. The production process of the coating is simple, raw material is cheap, so it is expected to get the scale of production. Understanding its mechanism and the existing problems is of great importance to replace imported products, reduce costs, and promote the development of new waterproof materials and waterproof technology.

\section{References}

[1]Xingwang Li, Yuqi Zhang, Ruijun Zhang. The Analysis on Material Formulation and Performance of LG Cementitious Capillary Crystalline Waterproofing Coating[J].China Building Waterproofing Industry, 2005, (11): 15-18.

[2]Shaozu Xue. The Analysis and Development of Foreign Cementitious Capillary Crystalline Waterproofing Materials[J]. China Building Waterproofing Industry. 2001, (6): 14-17.

[3]Ming Wu. Reflections on Cementitious Capillary Crystalline Waterproofing Coating[J]. China Building Waterproofing Industry, 2011, (17).

[4]Hongye Liu, The Analysis of Cementitious Capillary Crystalline Waterproofing Coating[D] .Xi'an University of Architecture and Technology,2004.

[5]Kai Zhang, Youkun You, Changwen Miao. The Analysis on Performance and Mechanism of Cementitious Capillary Crystalline Waterproofing Coating[J]. Concrete and Cement Products, 2004, (4):105-108. 